\title{
The Language of Essence and Inference in Mental Health: Natural Law- Legal Positivism-Cognitive Dissonance
}

\author{
Joseph Richard Crant \\ Canadian Psychological Association CPA
}

\begin{abstract}
K-12 Teachers are experiencing more stress than ever before, and the problem isn't expected to be going away anytime soon. In this article, I want to show how it is possible to re-stimulate damaged neural pathways using insights drawn from a newly developed cognitive model, and, to show anecdotal evidence from an ongoing longitudinal qualitative study that began in 2010. The original study was started to seek support and to validate the hypothesis that; cognition is equal to an emotional response to absurd notions, thoughts, idea, etc., and that; where the individual (mind) achieves resolve, the physical brain would rest, and the body would enter relaxation phase or the; "relaxation response" [1], equal to post fight or flight, thus allowing toxins to freely flush from the body through the urine as vital organs would become unstressed, and that resolve may be inherently human. It is in the study of Dementia and Alzheimer's disease which shows us that Neural pathways in the brain can become damaged, and/or lay dormant, and it is in this research and study that we believe that we have discovered a novel approach to assist in the problem of K-12 Teacher stress and mental health, by re stimulating dormant neural pathways which inherently make it possible to exist within this modern day environment without succumbing to the adverse effects of stress
\end{abstract}

\section{Introduction}

Beginning in 1987, hypothetical cognitive model/theory $\mathrm{C}=\mathrm{ea}^{2}$, was researched and developed over a thirty-year period of multidisciplinary experiential research and study by an "individual investigator" (Bejan, 2008), fist realized in 2009, $\mathrm{C}=\mathrm{ea}^{2}$ brings us closer to understanding the language of the subconscious mind, positing that; "a truer understanding of intent would have to involve empathy [2] as it is that "the ability to accurately infer the thoughts, intentions and emotional states of others has often been associated with the concept of empathy" (Morrison 2004). For each party to gain an adequate understanding of the other and that of what is being conveyed, under the influence of legal positivism regarding the teacher student relationship, empathy would play a vital role in communication, and serve as a buffering type of affect to offset the rigidity of some educational environments. Over a prolonged period, a society governed by legal positivism or; "the rule of law", will produce rigid systems [3] which shows up in political correctness, only to interfere with intimacy that, in turn, will create a static environment without empathy, as well as influence it's citizens to become cold and indifferent. At the other end of the spectrum and in comparison, natural or "moral law" governing a society will produce extremism through fundamentalism and dictatorship, and society over all would have a "cult like" essence. In a system or a society, Legal Positivism (LP) springs forth from Natural Law (NL) because of ignorance of traditional values and practices (ritual), and, the individual citizen living under LP and under stress, will investigate a return to NL seeking respite and relief from the stress within the mind, and the strain on the emotions, it is this that $\mathrm{C}=\mathrm{ea}^{2}$ points out as one cause of cognitive dissonance among some individuals, and today this is having adverse effects on the mental health of the teachers and, the students, as well as the rest of society in the form of collateral damage i.e. where an individual cannot act and behave in accordance to what can be understood as natural or "moral law", the individual will be disciplined according to legal positivism or "the rule of law" (cause and effect)".

We have been informed and educated throughout history about the need for balance in our individual lives, and for a balanced society, which quantified would mean that even on the molecular level, we need balance, now where we point this understanding in the direction of the mind of an individual, it becomes the mind body problem, and it is only with a theory where we can expect to establish a balance, this research and $\mathrm{C}=\mathrm{ea}^{2}$ strongly suggests, and will prove it true that realizing that "balance" is an inherent ability to maintain the "balancing act".

\section{Individual Case Studies 2010-2018}

\section{Nathan Bennett \\ Albright-Male- Oregon USA \\ PTSD 2011}

My familiarity with the author and with his research began in August 2011, when I lived in 
Thailand. At the time I was in the closing stages of a more than five-year long battle with major depression that had begun in 2006. In discussing $\mathrm{C}=\mathrm{ea}^{2}$ as a treatment for mental illness, I would like to discuss my own personal story, including the roots of my depression as well as the way in which information and insights gleaned from this study helped me determine ways of using the way my mind naturally worked for better mental health.

The Roots of Depression

Adequate

For me, the roots of my struggle with major depression go deep. Early childhood abuse led to a diagnosis of Post-Traumatic Stress Disorder at the age of four. From that time onward social difficulties and the repercussions of abuse meant that the raw material for depression (a constant sense of anxiety and worry) were present, and periodically in my life I have known prolonged periods of depression of some severity. Given that depression is a way the body slows down to recover from dealing with too much stress and pressure, it is no wonder that someone who has lived the sort of life that I have has faced depression on a regular basis.

Abuse brings with it a set of insoluble problems that require a great deal of thought. These problems include worries about love and identity, as well as ways of reacting to the world to defend ourselves from the dangers we face that many are simply unaware of. The added pressures and concerns make developing equilibrium more difficult, but there are other benefits that are often neglected as well.

In 2006, my father died at the age of 59. His death prompted a public examination of my life and childhood and widespread knowledge of child abuse and prompted a great deal of concern about my own longevity and chances for happiness and success in love. For the next five years I struggled with major depression, including occasional suicidal ideation, compounded by problems in work and family. The general difficulties of life along with the specific difficulties of my life seemed impossible to deal with, to the point where creative writing was difficult.

\section{The Treatment and Cure}

In discussing this work, the most helpful aspect to me was an understanding of the larger process by which our thoughts feed on themselves and cause depression and ways that equilibrium can be found to deal with them. I found that for myself, a great deal of conversation and writing was necessary to work out the difficulties in my own mind. There was nothing too mysterious in that aspect of the treatment.
What was of particularly greater interest was the physiological responses to the treatment. As my depression waned, for several weeks I had bad smelling and dark-colored urine, despite the large amount of water I was drinking, and the urine did not return to a normal color until after the feelings had returned to a state of basic mental health. Living abroad at the time and taking a close care of my health in that regard, I found the manifestation of systemic detoxification in relation to depression remission to be highly remarkable as a correlation.

\section{Wahidah Binti Abdrahim-Female-Malaysia Schizophrenia 2013}

Hello, I am Wahidah from Malaysia. I am 23 years old. I have a very serious problem in life and wish I get better. 6 years ago, since after high-school, I suffer from a bad depression, because my fibromyalgia and bipolar disorder became worse when I was 17. And woke up every day from sleep, feeling so bad, feverish all time. And as far as I could remember, I never sleep well in 6 years. I always had bad dreams, maybe it is because of thinking too much. I live in Perlis Malaysia, and to be honest, I am in a closed place and closed-minded people, in which, it is hard to find a suitable therapist to talk. It is very sad that, my doctor said I must take the pills, Seroquel 600mg and Epilim 1000mg per day and some other painkillers. And they warned me, if I didn't take my pills...I will be ill again. I was admitted into psychiatric ward 5 times since 2009 until 2012. If I take the pills as prescribed by the doctors, I never can have a life like others do. I cannot go study, I simply cannot enjoy life

March 29 / 2013

Last night was apparently a very short discussion. But I feel a little relief than I was before. I know I wasn't wrong to liberate myself from being controlled by any belief or religions. I wasn't wrong to ask people not to fear me with any hatred in the world. If it is about truth and sincerity, there is nothing to fear. And I know that I wasn't wrong to choose not to take Seroquel anymore. I believe that life is always possible. I believe I can get rid of my illness. And by believing in Miracles, life would be beautiful as it supposed to be. I wish to do everything I want. Go travels and enjoy the nature. Miracles shall happen. And I strongly believe in that.

\section{April/1/2013}

It takes about 24 hours for me to reflect myself. I mean, to re-think and re-think again after what has happened to me regarding the belief. And so, with all the facts I collected from holy books, the history of 
ancient people, and story of prophets, and by trusting my sense as a human being, and now I become stronger again. Not too depress and not too maniac. Middle, I eat middle, enjoy middle, do prayers and study religions middle, talk to my sister's middle much, and took medication lesser, and now, I think that I am much more normal than I was before, I sleep better. The brain is unlocked, and I am much happier!! :)

April/3/2013.

I feel much more calm, stronger. We are always where we need to be. I am too far from my best friends, and the only thing I can do is prayer. And never doubt on power of prayer, for prayer is such an energetic thought that may change the whole world. As simple as to believe that Hope never end.

\section{April/4/2013}

I still remember I just came out of psychiatric ward, and went out with my boyfriend and his sister, my boyfriend put our picture together, and a 'pious' brother was angry at me

He said, I better be insane than I break the law That was the reason why I tried suicidal, God loves me, I failed!

I swallowed 40-45 pills at one time but only sleep. One day when I was on car, and I intend in heart to suicide when I reached home, Car suddenly broke down

All of this made me believe in positive energy Great news,

I had a so much better sleep. For years I never slept soundly, today I slept enough and woke up not because of my spine telling me to get awake. One sleep, good sleep, enough sleep, I am confident that I may recover from illness, and enjoy life again. The Hope is always with me, and I believe in Hope. :)

April/6/2013

$\wedge \_4$ days consistently sound sleep :)

\section{April/7/2013}

Now is 4:23 am. I already slept for a few good hours and woke up early at this time. I was on vacation, alone, for past 2 days. My family unable to come with me, but I still enjoyed my vacation. I go to the beach, meet people, and last evening I returned home, then I went for hair color and SPA, and enjoying being wild and naughty sometimes :P Good days I had. And I begin to feel confident and more confident. The more I believe in myself, the more miracle seems to get attracted to me. And very good thing that, I be happy, excited, and not manic. Between January and April is the cycle of Manic. This year I t make it through, able to keep quiet.

\section{Final Entry}

April/12/2013

I am feeling happy with this study. And now, I get the answers I want from this study. This study makes me feel better, everything as I wrote on previous journal. This study really brought me into a new world. Because, it proves that whatever around me, and what I was taught during my childhood, everything is related to each other.

\section{Jon Elder-Male-Pennsylvania USA PTSD 2013}

I'm 35 and work as a biomedical engineer. I was recently discharged from the Air Force with PTSD and have worked to investigate alternative methods to combat my anxiety; this has resulted in a great deal of grad school work, and independent study in orthomolecular psychology and the mind body problem from a psychoanalytic view. So glad to be here and I look forward to discussions.

May 13, 2013

All things are connected, none more so than the relationships we share with our friends, family, and community itself. This relationship however goes both ways we not only effect those around us, but in turn are affected. In terms of correlational emotional distress as society has become more isolated and autonomous, I believe many factors from depleted toxic soil, air, and water and its subsequent manifestation in food like products that leave us depleted of crucial amino acids, vitamins and nutrients. An ironic mirror of the toxic soul of those who have sown the seeds of their own fate.

May 13, 2013

I believe it is the best and possibly the only hope our planet has given the radical militarization and consolidation of power we've witnessed the last few decades. The best way of changing society begins with personal change toward wholeness, equilibrium and emotional maturity, and somehow spreading that catalyst virally to everyone around us. Only then will we defeat the old paradigm by making it obsolete.

\section{Final Entry}

\section{Aug 1, 2013 10:55 AM EDT}

It's been a very strange and excellent time. I've been more relaxed, hardly eat, and am clear headed 
enough to select who and what I choose to give my attention. I've noticed rancid urine, and a lack of appetite, and I feel slightly detached yet calm. Ironically, it's steered my life in a totally new direction. My time in the military seems like a bad dream that I'm glad to be awakened from. I usually now only eat once a day or so. I eat when I think I should rather than when my body wants. I've been urinating a lot, not a little here and then either. I'm talking "drinking beer all night flow", without the beer

\section{Lee Riddolls-Male-Canada Ankylosing Spondylitis 2016}

I was diagnosed nineteen years ago with autoimmune disease Ankylosing Spondylitis, which is chronic arthritis. At the time of the study it was during a period when I would go off my pain medication, and usually it is a week in hell but this time it was different, the pain was so minimal that I was able to begin lifting weights again and I had no depression and was able to sleep. After the bout of detoxifying, I felt much better and had a better sense of understanding life in general I would say.

It's been about one month since I stopped urinating as much and the pain is not as intense as it was before I came into this study. I am looking forward to seeing how far this research can help me and every day I hope for total recovery.

\section{Paul Arsenault}

\section{Depression, Anxiety 2018}

The experience of being a part of this research has helped me to better understand how I make decisions and has had a positive and beneficial effect on my emotional and physical health

After a period of discussions, I began to realize a sense of calm where in my life and because of the business that I am working in, I mostly stressed. I was surprised when I began noticing the color of my urine had changed and become darker than normal because I always try to keep well hydrated and drink lots of water. My urine had a foul odor, and I was going to the bathroom quite a lot more than I usually do.

I was only involved with the study for about eight weeks until the detoxification started, and shortly after I began to feel clear headed and able to think things through with more accuracy. I would like to learn more about $\mathrm{C}=\mathrm{ea}^{2}$ to gain more knowledge of the brain and how it is connected to the body's health. The detoxification lasted quite a while and I was surprised because I have always felt that I eat well.

I believe this research has great potential to help people with mental health problems as it has helped me with anxiety in such a short time.

\section{Joseph Richard Crant-Male-Canada Depression, Anxiety}

It was because of my own experience with mental health while growing up in Ontario Canada, that I first began researching however, It was not to find relief for myself, it was to protect my own children from negative affect of bullying, I believed that I could inform and educate them about why some people could be so mean, I had no idea that it would come to what it has today.

All I want to say is that on the day where I had first noticed something different about how I was feeling, I literally blurted out; "is this what it's like to feel normal?" It felt like everything associated with fear, anxiety, depression, suspicion, superstition, was gone in an instant. A few weeks later, toxins started to flush from my body through the urine, and I thought I had an infection. A urine test did not show infection, the condition persisted for about three weeks with pain and pressure in the lower abdomen, frequent urination and foul odor. A second testing also indicated no infection.

\section{Natures Paradigm}

Soon after the detoxing episode, I had developed a "sense of detachment yet of calm" as reported here by case study Jon Elder, and the same as with Nathan Albright, "I noticed my sense of humor returning". With the weight loss, my body began to trim up and my core strengthened, lifting and carrying heavy things at work (construction) was much easier, Lee Riddolls; stated "I was able to begin lifting weights again". It took me a while but since the "flush" in 2009, and the same as what Paul Arsenault had reported here, "this research has helped me to better understand how I make decisions".

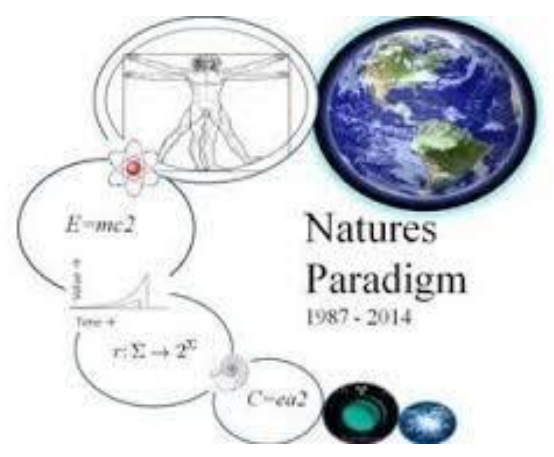

Around 2009, I saw what I believed to be a connection between $\mathrm{C}=\mathrm{ea}^{2}$, Equilibrium theory, John Nash (1950) and energy equivalency $\mathrm{E}=\mathrm{mc}^{2}$, and called it "Natures Paradigm" to suggest hypothetically; from elementary particles, we become conscious and "develop cognitive abilities" as basic needs drive us to seek understanding of the 
environment, $\left(\mathrm{C}=\mathrm{ea}^{2}\right)$, second we integrate and adapt to the environment by struggle to meet "Equilibrium", (Nash), and eventually, it becomes possible to live within this earth environment; conscious, in balance with nature, or " in tune with the universe", evolving into an efficient ecosystem, $\left(\mathrm{E}=\mathrm{mc}^{2}\right)$, experience a second cognitive evolution, $\left(\mathrm{C}=\mathrm{ea}^{2}\right)$, and complete the balance with nature, (Nash Equilibrium) [4] to live out the rest of our life in health.

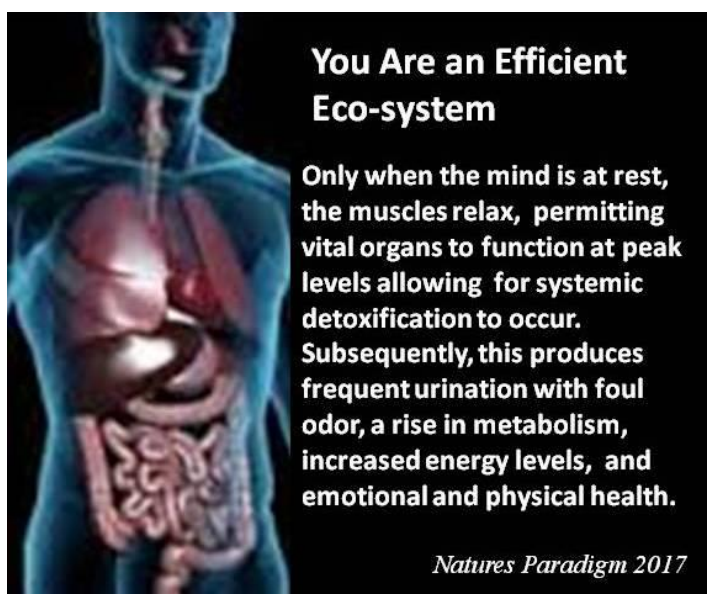

As biological organisms, it is understandable that it may be in our natural state to seek solitude and be at rest, and as cognitive organisms or "thinking beings", we must have ability to re-solve complex problems else we stagnate and retard or decay in some manner as aging poorly would dictate and show up in diseases.

$\mathrm{C}=\mathrm{ea}^{2}$ The Way Forward: A Discussion of

Approaches

September 19, 2017

By Nathan Albright

The current state of research of this theory is largely based on self-reporting from people like me that can be considered as a case study approach. We have stories of depression, therapeutic conversations that help re-orient attention from depression as a crisis to it being a response to the absurdity and difficulty of life that provides a period of rest where recuperation can be undertaken for the stresses of life, and where recovery was accompanied by the body ridding itself of what appeared to be toxins that were associated with the depression, after which there was a restoration to generally neutral to positive feelings. Since then, I have not had any prolonged period of major depression thus far, and recovery from somewhat low feelings lasting for several days at a time has also been associated by what appeared to be the body cleansing itself of certain toxins. I have not yet been able to have these tested, but that is something that I believe would be worthwhile in the future.

Stories like my own, and that of others, have a certain power to them. For example, a paper published in the Journal of Behavioral Health Services in April 2011 found a positive role in selfreported mental health measures in predicting functional outcomes for veterans. It should be noted that just as I have struggled with PTSD since early childhood, so veterans too are often found to struggle with it, and this struggle is often related to other mental health issues with anxiety and depression. Placing one's story in a context often helps to make it easier to cope with, and it also can provide therapeutic benefit for oneself and for others. Although this approach is qualitative instead of quantitative, there are positive results from being able to express one's story and share it with others and, also, to gain insights from the stories of others, especially where there are similar patterns that may be recognized between a variety of self-reported stories.

Nevertheless, there are some limitations in reliance upon self-reporting and the case study approach. An oft-repeated truism is that correlation is not causation, and there are limits to the evidence that can be gathered when one is limited to the casestudy approach. Questions of mechanism as well as numerical data are difficult to determine, and there can be a certain vagueness that comes from only being able to express one's experience in a story without there being any data that can be aggregated together and analyzed in detail as part of experimental research. In that light, one could see the efforts at helping people who have prolonged and/or deep periods of major depression ought to take advantage of as many approaches as possible, both qualitative approaches that allow them to report on their own mental and emotional state as well as quantitative approaches that can provide a detailed and data-driven understanding of how the recovery from major depression appears in various measurements.

\section{Suggestions for Future Research}

I would like to briefly discuss some suggestions for future research to further integrate this paradigm regarding depression into existing studies. As many of the cases so far in the body of research that Crant has developed so far in his studies of depression include what appears to be the passing of foulsmelling urine, urine analysis related to the recovery of major depression is an obvious area of potential research. Such analysis would be able to help relate depression to physical causes related to the chemical contents of the body and point to the importance of the body's natural systems in helping to preserve mental health. Likewise, the existing body of case 
studies, and further case studies that are undertaken, can be examined using correlational studies that seek to determine the common elements in the story. If similar processes and events can be found to occur in a sizable body of people recovering from major depression, then it may be possible to find certain avenues of approach for further research that would help to point out the mechanisms by which the body seeks to rest and recover through depression and then is able to rid itself of that which is dragging it down. On a less chemical and statistical level, we may view the therapeutic efforts of reframing thoughts and ideas about depression as an approach that shows some marked similarities to Cognitive Behavioral Therapy, a common approach undertaken in various mood disorders like depression and anxiety disorders that seeks to give the mind a greater amount of tools in order to better understand the absurdity of life and the need to be resilient in the face of life's stresses and difficulties. Finally, the coincidence of PTSD and depression in athletes and soldiers is something that has been noted in the groundbreaking research on CTE by Dr. Bennet Omalu, most famous for being the doctor who first discovered the problem with repeated brain trauma in sports. His papers on Chronic Traumatic Encephalopathy in athletes and veterans has suggested that traumatic experiences can cause the development of tau proteins in the brain that are associated with depression and other mental illnesses, which may provide a physiological basis for a great deal of our understanding of PTSD and related mental illnesses. These are all among the areas where future research may be very profitable [5].

\section{Conclusion}

Hypothetical cognitive model/theory $\mathrm{C}=\mathrm{ea}^{2}$ supplies multiple perception models and insights, and when delivered in educational course study, discussion and discourse, is effective in the remission of mental health and other conditions in some individuals. Physical manifestation of systemic detoxification is possible where the individual can achieve resolution of complex human problems and/or issues when utilizing $\mathrm{C}=\mathrm{ea}^{2}$ as a model for decision making. $\mathrm{C}=\mathrm{ea}^{2}$ suggests being a pathway to permit the physical body enter relaxation response [6] where and Theta is sustained in the individual, and systemic detoxification becomes possible because of gaining new insight into human behavior.

Supporting Research $\mathbf{C}=\mathbf{e a}^{2}$

Depression and Entropy

Epiphenomenon

Autonomous vs Rote Learning

Human Development

Rumination and Mental Illness

Schizophrenia and $\mathrm{C}=\mathrm{ea} 2$
Spirituality

The Four Brain States

The Paradoxical human

What is Depression?

Fine-tuned Universe

Bio-psychodynamics

Natural Sequential Experience

Emotional Force Values

Benefits of $\mathrm{C}=\mathrm{ea} 2$

\section{Acknowledgements}

Drew Tapley M.A., Nathan Albright M.A. B.S. M.S., Adrian Bejan PhD, Tanja Haley PhD

Stephen Kaduulli M.A. B.A., Noreen Kassam M.A. B.S. M.S., Rita S. Stark M.S. B.S.

\section{References}

[1] The Relaxation Response: History, Physiological Basis and Clinical Usefulness Herbert Benson, First published: January/December 1982, https://doi.org/ 10.1111/j.0954-6820.1982.tb00378.x

[2] Morrison, J., (2004). Understanding Others by Understanding the Self: Neurobiological Models of Empathy and their Relevance to Personality Disorders, https://www.ncbi.nlm.nih.gov/pmc/ articles/PMC2538737/

[3] Legal stability and predictability are a fundamental part of "what people mean by the Rule of Law” (Schwarzschild 2007, 686)

[4] Holt, C.A., Roth, A.E., (2004). The Nash equilibrium: A perspective, https://doi.org/10.1073/ pnas.0308738101

[5] https://edgeinducedcohesion.blog/2017/09/19/ cea2-the-way-forward-a-discussion-of-approaches/

[6] The Relaxation Response: History, Physiological Basis and Clinical Usefulness Herbert Benson, First published: January/December 1982, https://doi.org/ 10.1111/j.0954-6820.1982.tb00378.x 